\title{
Unil
}

UNIL | Université de Lausanne

Unicentre

$\mathrm{CH}-1015$ Lausanne

http://serval.unil.ch

Year : 2011

\section{Reproducibility of Acute Mountain Sickness in Children and Adults: A Prospective Study}

\author{
GARCIN Sophie
}

GARCIN Sophie, 2011, Reproducibility of Acute Mountain Sickness in Children and Adults: A Prospective Study

Originally published at: Thesis, University of Lausanne

Posted at the University of Lausanne Open Archive.

http://serval.unil.ch

\section{Droits d'auteur}

L'Université de Lausanne attire expressément l'attention des utilisateurs sur le fait que tous les documents publiés dans I'Archive SERVAL sont protégés par le droit d'auteur, conformément à la loi fédérale sur le droit d'auteur et les droits voisins (LDA). A ce titre, il est indispensable d'obtenir le consentement préalable de l'auteur et/ou de l'éditeur avant toute utilisation d'une oeuvre ou d'une partie d'une oeuvre ne relevant pas d'une utilisation à des fins personnelles au sens de la LDA (art. 19, al. 1 lettre a). A défaut, tout contrevenant s'expose aux sanctions prévues par cette loi. Nous déclinons toute responsabilité en la matière.

\section{Copyright}

The University of Lausanne expressly draws the attention of users to the fact that all documents published in the SERVAL Archive are protected by copyright in accordance with federal law on copyright and similar rights (LDA). Accordingly it is indispensable to obtain prior consent from the author and/or publisher before any use of a work or part of a work for purposes other than personal use within the meaning of LDA (art. 19, para. 1 letter a). Failure to do so will expose offenders to the sanctions laid down by this law. We accept no liability in this respect. 


\title{
Reproducibility of Acute Mountain Sickness in Children and Adults: A Prospective Study
}

\author{
THESE
}

Préparée sous la direction du Professeur Associé Urs Scherrer

Et présentée à la Faculté de Biologie et de Médecine de Lausanne pour l'obtention du grade de

DOCTEUR EN MEDECINE

Par

Sophie GARCIN

Médecin diplômé de la Confédération Suisse

Originaire de Lancy, Genève

Lausanne 


\title{
Reproducibility of Acute Mountain Sickness in Children and Adults: A Prospective Study
}

\author{
THESE
}

Préparée sous la direction du Professeur Associé Urs Scherrer

Et présentée à la Faculté de Biologie et de Médecine de Lausanne pour l'obtention du grade de

DOCTEUR EN MEDECINE

Par

Sophie GARCIN

Médecin diplômé de la Confédération Suisse

Originaire de Lancy, Genève

Lausanne

2011 


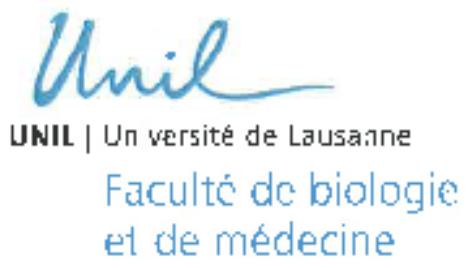

Ecole Doctorale

Doctorat en médecine

\section{Imprimatur}

Vu le rapport présenté par lé jury d'cuntent, composé de

Directeur de tilese Mansizur le Profesweur Urs Scherrer

Co-lirecteur de these

Expert Monsietr te Professen Berbard Waeber

Directrice de PCole Madsme Te Professeur Stephanie Clarke doctorale

la Commission MD de l'Lcole doctorale antorise ?'intpression de la thèse de

\section{Madame Sophie Garcin}

intitulée.

Reproducibility of Acute Mountain Sickness in Children and Adults: A Prospective Study

T.ausanne, le 10 janvier 2012

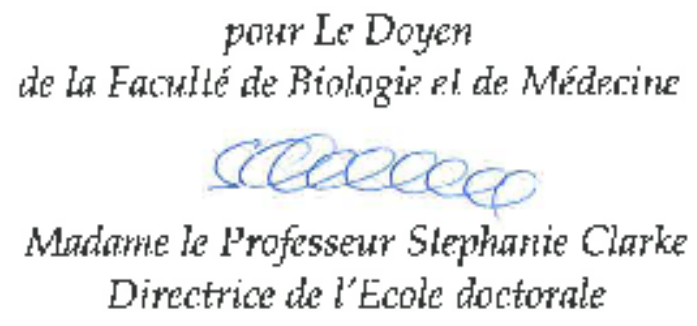




\section{Résumé}

Objectif : Alors qu'un antécédent d'AMS est couramment utilisé pour fournir des conseils et recommander une prophylaxie médicamenteuse pour les expositions ultérieures à la haute altitude, la reproductibilité intra-individuelle de l'AMS au cours d'expositions répétées n'a jamais été examinée dans une étude prospective contrôlée.

Méthodes : Chez 27 enfants et 29 adultes non acclimatés, nous avons évalué la présence et la sévérité de l'AMS durant les 48 premières heures après une montée rapide à $3450 \mathrm{~m}$, et ceci en deux occasions distantes de 9 à 12 mois.

Résultats : 18 adultes ( $62 \%$ ) et 6 enfants ( $22 \%$ ) ont souffert d'AMS durant la première exposition et 14 adultes ( $48 \%$ ) et 4 enfants ( $15 \%$ ) durant la seconde ( $\mathrm{P}=0.01$, adultes versus enfants). Mais surtout, la reproductibilité intra-individuelle de l'AMS était très différente $(\mathrm{P}<0.001)$ entre les deux groupes ; en effet, aucun des 6 enfants ayant souffert d'AMS au cours de la première exposition n'en n'a souffert au cours de la seconde mais 4 enfants sans AMS lors de la première exposition ont été touchés lors de la seconde exposition. Contrairement à cela, 14 des 18 adultes qui ont souffert de l'AMS lors de la première exposition ont également présenté ce problème au cours de la seconde et aucun nouveau cas ne s'est développé dans ceux qui n'avaient pas souffert de cette affection lors de la première occasion.

Conclusion : Si chez l'adulte, un antécédent d'AMS a une bonne valeur prédictive d'un nouvel épisode durant les expositions futures dans des conditions similaires, il n'en est pas de même chez l'enfant chez lequel il n'a pas de valeur prédictive. Un antécédent d'AMS ne devrait donc pas inciter les praticiens à déconseiller la réexposition ou à prescrire une prophylaxie médicamenteuse chez l'enfant. 


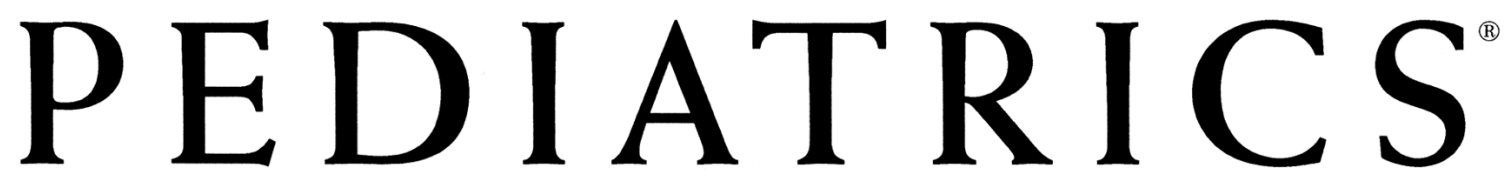

OFFICIAL JOURNAL OF THE AMERICAN ACADEMY OF PEDIATRICS

\section{Reproducibility of Acute Mountain Sickness in Children and Adults: A Prospective Study}

Emrush Rexhaj, Sophie Garcin, Stefano F. Rimoldi, Hervé Duplain, Thomas Stuber, Yves Allemann, Claudio Sartori and Urs Scherrer

Pediatrics; originally published online May 2, 2011;

DOI: $10.1542 /$ peds.2010-3756

The online version of this article, along with updated information and services, is located on the World Wide Web at:

http://pediatrics.aappublications.org/content/early/2011/04/27/peds.2010-3756

PEDIATRICS is the official journal of the American Academy of Pediatrics. A monthly publication, it has been published continuously since 1948. PEDIATRICS is owned, published, and trademarked by the American Academy of Pediatrics, 141 Northwest Point Boulevard, Elk Grove Village, Illinois, 60007. Copyright ( $) 2011$ by the American Academy of Pediatrics. All rights reserved. Print ISSN: 0031-4005. Online ISSN: 1098-4275.

\section{American Academy of Pediatrics}

DEDICATED TO THE HEALTH OF ALL CHILDREN ${ }^{\mathrm{m}}$ 


\section{Reproducibility of Acute Mountain Sickness in Children and Adults: A Prospective Study}

AUTHORS: Emrush Rexhaj, MD, ${ }^{\text {a }}$ Sophie Garcin, MD, ${ }^{\text {a }}$ Stefano F. Rimoldi, MD, ${ }^{a, b}$ Hervé Duplain, MD, ${ }^{a}$ Thomas Stuber, MD, ${ }^{\text {Y }}$ Yves Allemann, MD, ${ }^{\text {b }}$ Claudio Sartori, MD, ${ }^{\text {a }}$ and Urs Scherrer, MD ${ }^{a, c}$

aDepartment of Internal Medicine, Centre Hospitalier Universitaire Vaudois, Lausanne, Switzerland; 'bSwiss Cardiovascular Center Bern, University Hospital, Bern, Switzerland; and ${ }^{c}$ Facultad de Ciencias, Departamento de Biología, Universidad de Tarapacá, Arica, Chile

KEY WORDS

acute mountain sickness, altitude, children, prevalence

\section{ABBREVIATIONS}

AMS-acute mountain sickness

$\mathrm{Cl}$-confidence interval

Drs Rexhaj and Garcin contributed equally to this work.

Drs Rexhaj, Sartori, and Scherrer provided study concept and design. Drs Rexhaj, Garcin, Rimoldi, Duplain, Stuber, and Sartori conducted acquisition of data. Drs Rexhaj, Garcin, Rimoldi, Allemann, Sartori, and Scherrer performed the analysis and interpretation of data. Drs Rexhaj, Garcin, and Scherrer drafted the manuscript. Drs Sartori, Duplain, Allemann, and Stuber provided critical revision of the manuscript for important intellectual content. Drs Rexhaj and Rimoldi performed statistical analysis. Drs Sartori and Scherrer obtained funding. Drs Duplain and Stuber contributed administrative, technical, or material support. Drs Scherrer and Sartori performed study supervision. All authors provided final approval of the version to be published.

www.pediatrics.org/cgi/doi/10.1542/peds.2010-3756

doi:10.1542/peds.2010-3756

Accepted for publication Feb 8, 2011

Address correspondence to Urs Scherrer, MD, Department of Internal Medicine, BH 10.642, CHUV, CH-1011 Lausanne, Switzerland. E-mail: urs.scherrer@chuv.ch

PEDIATRICS (ISSN Numbers: Print, 0031-4005; Online, 1098-4275). Copyright (C) 2011 by the American Academy of Pediatrics FINANCIAL DISCLOSURE: The authors have indicated they have no financial relationships relevant to this article to disclose.

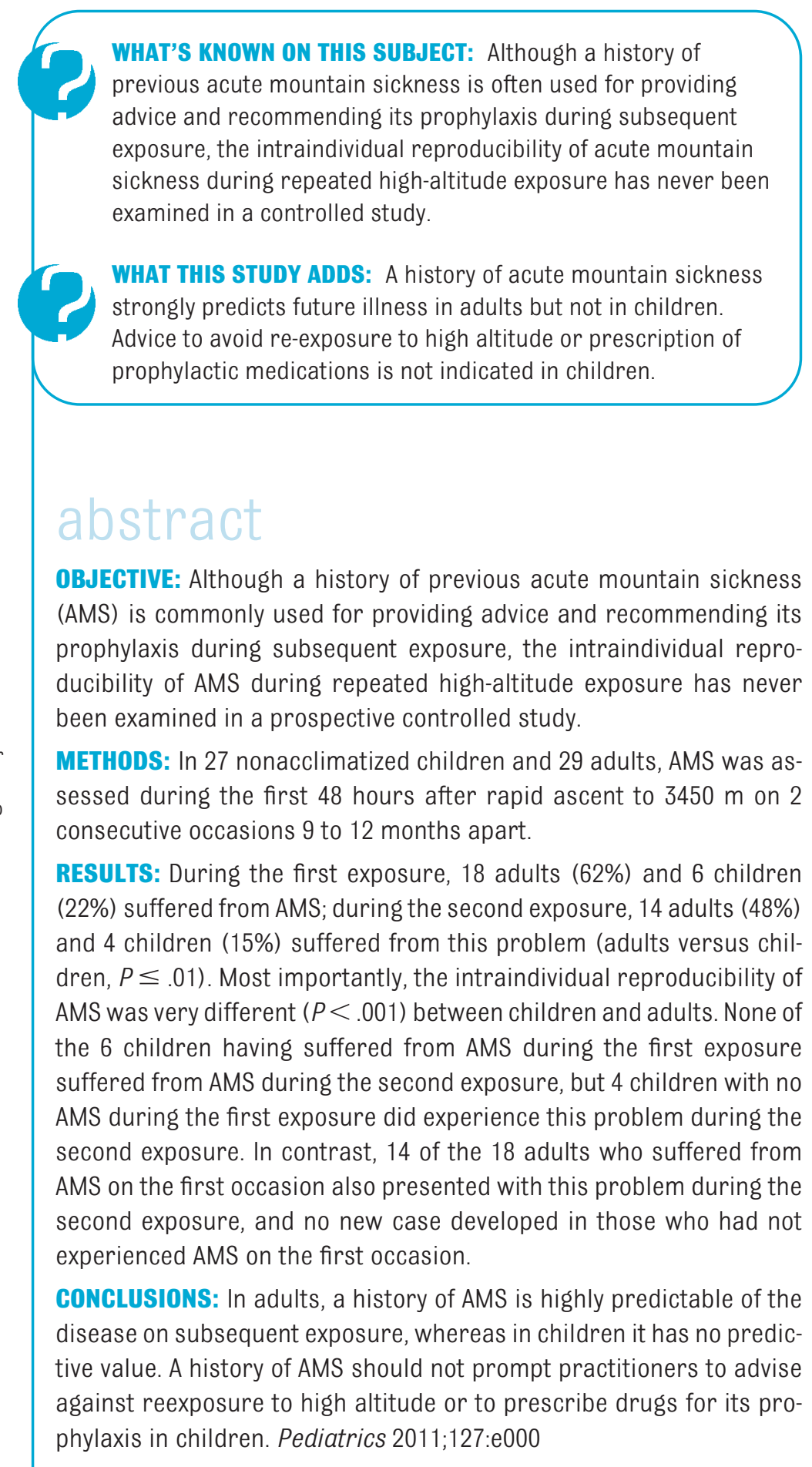

WHAT'S KNOWN ON THIS SUBJECT: Although a history of previous acute mountain sickness is often used for providing advice and recommending its prophylaxis during subsequent exposure, the intraindividual reproducibility of acute mountain sickness during repeated high-altitude exposure has never been examined in a controlled study.

WHAT THIS STUDY ADDS: A history of acute mountain sickness strongly predicts future illness in adults but not in children. Advice to avoid re-exposure to high altitude or prescription of prophylactic medications is not indicated in children.

OBJECTIVE: Although a history of previous acute mountain sickness (AMS) is commonly used for providing advice and recommending its prophylaxis during subsequent exposure, the intraindividual reproducibility of AMS during repeated high-altitude exposure has never been examined in a prospective controlled study.

METHODS: In 27 nonacclimatized children and 29 adults, AMS was assessed during the first 48 hours after rapid ascent to $3450 \mathrm{~m}$ on 2 consecutive occasions 9 to 12 months apart.

RESULTS: During the first exposure, 18 adults (62\%) and 6 children (22\%) suffered from AMS; during the second exposure, 14 adults (48\%) and 4 children (15\%) suffered from this problem (adults versus children, $P \leq .01$ ). Most importantly, the intraindividual reproducibility of AMS was very different $(P<.001)$ between children and adults. None of the 6 children having suffered from AMS during the first exposure suffered from AMS during the second exposure, but 4 children with no AMS on the first occasion also presented with this problem during the AMS on the first occasion also presented with this problem during the second exposure, and no new case developed in those who had not experienced AMS on the first occasion.

CONCLUSIONS: In adults, a history of AMS is highly predictable of the disease on subsequent exposure, whereas in children it has no predictive value. A history of AMS should not prompt practitioners to advise phylaxis in children. Pediatrics 2011;127:e000 
Travel to high-altitude destinations for business and recreational purposes has become increasingly popular, and large numbers of persons are exposed to high-altitude-related medical risks. Among these risks, acute mountain sickness (AMS) is by far the most frequent problem occuring in more than $80 \%$ of tourists arriving by plane at $3740 \mathrm{~m} .{ }^{1}$ AMS is a syndrome of nonspecific symptoms, including headache and 1 or more of the following: fatigue, anorexia and nausea, dizziness, and sleep disturbance, often developing within hours after arriving at altitudes $>2500 \mathrm{~m}^{2}{ }^{2}$ It affects otherwise healthy persons and in most cases resolves spontaneously, but in some cases it progresses to life-threatening highaltitude cerebral edema. ${ }^{2} \mathrm{~A}$ history of AMS is often used for providing advice about the risk of its reoccurrence and deciding about the indication for its pharmacologic prophylaxis during subsequent high-altitude exposure; to the best of our knowledge, however, there is surprisingly little information on the intraindividual reproducibility of AMS during repeated high-altitude exposure in adults, 3,4 and no such information in children. In a prospective, controlled study, we therefore assessed the prevalence of AMS in nonacclimatized children and adults with no previous high-altitude experience during the first 48 hours after rapid ascent by train to $3450 \mathrm{~m}$ on 2 consecutive occasions 9 to 12 months apart.

\section{METHODS}

\section{Study Group}

We studied 27 healthy Swiss children (mean [SD] age: 12 [2] years; range: 8-16 years; 20 girls; height: 150 [14] cm; weight: 43.0 [11.4] kg; BMI: 19.8 [2.6]) and 29 healthy Swiss adults (mean [SD] age: 39 [8]; range: 26-63 years; 11 women; height: 175 [8] cm; weight: 71.9 [11.7] kg; BMl: 23.5 [2.9]). All participants had regular physical activity and were living at altitudes $<700 \mathrm{~m}$. None of the participants was obese (BMI >30), had slept at high altitude $(>1500 \mathrm{~m})$ during the 3 months preceding the 2 studies, none had ever spent a night at an altitude $>2000 \mathrm{~m}$, and none was taking any medication during the studies. The experimental protocol was approved by the Institutional Review Board on Human Investigation, and all participants (including the children as well as their parents) provided written informed consent.

The study took place on 2 consecutive occasions 9 to 12 months apart. The participants ascended with a $2 \frac{1}{2}$-hour train ride that took them from $568 \mathrm{~m}$ to the Jungfraujoch International High Altitude Research Station at $3450 \mathrm{~m}$, where they arrived in the early afternoon. They then spent 2 days and 2 nights in small bedrooms at the research station. During the stay, all participants received the same diet, and care was taken to assure adequate fluid intake $(\geq 2 \mathrm{~L} / \mathrm{d})$. Adult participants refrained from alcohol consumption at high altitude. Physical activity was standardized. On the day of arrival, the participants rested quietly and visited the research station and the adjacent installations. In the afternoon of the second day, all participants made an easy 2- to 21/2-hour walk to the Mönchsjoch Hut located at $3650 \mathrm{~m}$. On the morning before descent the participants remained within the research station.

\section{Evaluation for Acute Mountain Sickness}

The presence of AMS was assessed on the evening of the day of arrival and on the 2 following mornings (at 6, 18, and 42 hours after arrival at high altitude) with a French version of the Lake Louise Scoring System, a selfassessment questionnaire, ${ }^{5}$ under the supervision of a trained examiner.
Briefly, for each of the 5 items (headache, gastrointestinal symptoms, fatigue, dizziness, and sleep disturbance), the participants noted a score between 0 and 3 , with 0 indicating the absence of the symptom; 1 , mild symptoms; 2 , moderate symptoms; and 3 , severe, incapacitating symptoms. For children younger than 12 years of age, a verbally adapted version of the score was used (Lake Louise age-adjusted symptom score). ${ }^{6}$ Participants were considered suffering from AMS if they were experiencing headache and scored $\geq 3$ on the selfassessment questionnaire (the maximal score for the questionnaire was 15) on at least 1 of the 3 assessments. ${ }^{5}$

\section{Measurement of Arterial 0xygen Saturation}

Transcutaneous arterial saturation and heart rate were measured at a fingertip with a pulse oximeter (0xiMax N-595, Nellcor, Pleasanton, CA).

\section{Statistical Analysis}

Statistical analysis was performed by using paired and unpaired Student's $t$ tests for within- and between-group comparisons of normally distributed variables. The Fisher's exact test was used for between-group comparisons of the prevalence and reproducibility of AMS. Predictive values and confidence intervals (Cls) were calculated as previously described.? Data are expressed as mean (SD). A $P$ value $<0.05$ was considered to indicate statistical significance.

\section{RESULTS}

Arterial oxygen saturation at high altitude was similar in children (90\% [2\%] [95\% Cl: 86\%-94\%]) and adults (90\% [3\%] [95\% Cl: 84\%-93\%]), whereas heart rate, as expected, was more rapid ( $P<$ .001) in children (99 [12] beats per minute [95\% Cl: $75-122$ beats per minute]) than in adults (80 [9] beats per minute [95\% Cl: $76-85$ beats per minute]).

All subjects completed the Lake Louise questionnaire during both exposures. 
Children

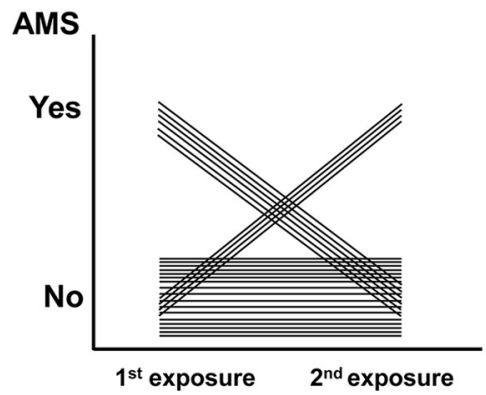

\section{Adults}

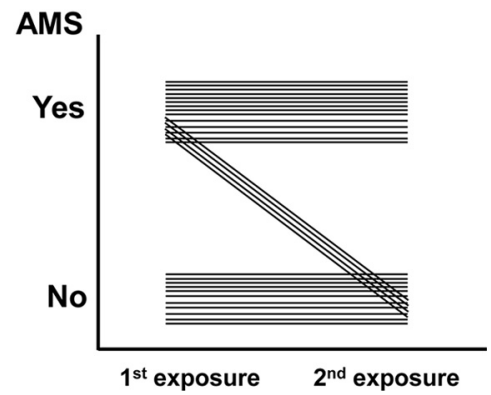

FIGURE 1

Schematic representation of the presence or absence of AMS in 27 children and 29 adults during the first 48 hours after rapid ascent by train from 568 to $3450 \mathrm{~m}$ during 2 subsequent exposures 9 to 12 months apart. Each line represents a subject.

The overall prevalence of AMS was significantly higher in adults than in children. During the first exposure, 18 of the 29 adults (62\%) and 6 of the 27 children (22\%) suffered from AMS $(P=.003)$; during the second exposure, 14 adults (48\%) and 4 children (15\%) suffered from this problem ( $P=$ .01) (Fig 1). The intraindividual reproducibility of AMS was markedly different between children and adults $(P<$ .001; Fig 1). In children, a history of AMS did not predict its recurrence, because none of the 6 children having suffered from AMS during the first exposure suffered from AMS during the second exposure. However, 4 children, who had not suffered from AMS during the first exposure, experienced it during the second exposure (positive predictive value: $0 \%$ [95\% Cl: $0 \%-48 \%$ ]; negative predictive value: $81 \%$ [95\% Cl: $57 \%-94 \%]$ ]. In contrast, AMS was very reproducible in adults; 14 of the 18 adults who suffered from AMS on the first occasion also presented with this problem during the second exposure, and no new cases developed in those adults who had not suffered from AMS on the first occasion (positive predictive value: $78 \%$ [95\% Cl: 52-93\%]; negative predictive value: $100 \%$ [95\% Cl: 68\%-100\%]). In children and adults, the prevalence of AMS was similar in both genders.

Among the participants who suffered from AMS, the severity of the disease was similar in children and adults during both exposures; during the first exposure, the mean (SD) score was 3.8 (1.2) $(95 \% \mathrm{Cl}: 3-6)$ in children and 4.6 (1.4) (95\% Cl: $3-8)$ in adults ( $P=.24$ ); during the second exposure it was 4.3 (1.0) (95\% Cl: 3.0-5.0) and 4.4 (1.4) (95\% Cl: $3.0-7.0)$, respectively ( $P=$ .78). None of the subjects developed clinical signs of high-altitude cerebral or pulmonary edema.

Independent of whether AMS was present or not, headache and sleep disturbances were more severe $(P<.001)$ in adults than in children: mean headache score was $0.86(0.83)$ versus 0.30 (0.57) (95\% Cl: $0.0-2.1$ vs $0.0-2.0$ ) and sleep disturbance score was 1.07 (0.83) versus 0.39 (0.68) (95\% Cl: $0.0-$ 2.1 vs $0.0-2.0$ ), whereas the scores for gastrointestinal symptoms, fatigue, and dizziness were similar in the 2 groups. Moreover, headache was also significantly $(P=.006)$ more frequent in adults (23 of 29) than in children (11 of 27), whereas the frequency of the other 4 symptoms making up for AMS was similar in children and adults.

\section{DISCUSSION}

AMS is a frequent problem in travelers ascending to high-altitude locations. Its occurrence during previous exposure is commonly used for providing advice and deciding about the indication for its prophylaxis during subse- quent exposures, but there is little information on its intraindividual reproducibility. ${ }^{2}$ In this prospective controlled study, we found that the intraindividual reproducibility of AMS was very different between children and adults. Although nearly $80 \%$ of the adults who had suffered from AMS during the first exposure also suffered from this problem during the second exposure, none of the children who had suffered from AMS on the first occasion suffered from this problem again. These findings indicate that AMS history is useful for providing advice and to guide the prescription of drugs for its prophylaxis in adults but not in children.

Our data indicate that, in adults, AMS history not only allows to predict with a high probability its recurrence during subsequent exposure; it also allows excluding its occurrence in those who had not suffered from this problem, because none of the adults who had not suffered from AMS during the first exposure suffered from this problem during the second exposure. In contrast, in children not suffering from AMS during the first exposure did not exclude its occurrence during subsequent exposure, as demonstrated by the 4 children who were asymptomatic during the first exposure but suffered from AMS during the second exposure. The reason for this difference of the intraindividual reproducibility of AMS between children and adults is not clear but could possibly involve variability in the self-perception of illness in children. ${ }^{8}$

The present data also provide the first direct comparison of the prevalence of AMS between children and adults under strictly controlled conditions. The markedly lower prevalence of AMS in children than in adults was unexpected, because it has been suggested that the incidence of AMS may be inversely related to age. ${ }^{9}$ This finding 
does not seem to be related to a particularly high prevalence of AMS in adults in the present study, because it was similar or lower than the one reported in previous studies. ${ }^{1,10}$ It was also not related to an unexpectedly low prevalence of AMS in children in the present study, because the prevalence of AMS was similar to the one reported in an earlier study at this altitude. ${ }^{11}$

In this controlled study, we were able to control for several important confounding factors that may facilitate or mimic AMS. Exercise represents a risk factor for AMS, and more intense exercise has been suggested to explain the higher prevalence of AMS in young versus elderly mountaineers in an earlier study. ${ }^{12}$ Here, we found that when exercise is controlled, the AMS prevalence was lower in children than in adults. In adults, alcohol consumption may ag-

\section{REFERENCES}

1. Murdoch DR. Altitude illness among tourists flying to 3740 meters elevation in the Nepal Himalayas. J Travel Med. 1995;2(4): 255-256

2. Hackett PH, Roach RC. High-altitude illness. N Engl J Med. 2001;345(2):107-114

3. Forster P. Reproducibility of individual response to exposure to high altitude. $\mathrm{Br} \mathrm{Med}$ $J$ (Clin Res Ed). 1984;289(6454):1269

4. Robinson SM, King AB, Aoki V. Acute mountain sickness: reproducibility of its severity and duration in an individual. Aerosp Med. 1971;42(7):706-708

5. Roach RC, Bärtsch P, Hackett PH, Oelz 0. The Lake Louise acute mountain sickness scoring system. In: Sutton JR, Houston CS, Coates G, eds. Hypoxia and Molecular Medicine. Burlington, VT: Queen City; 1993:272-274

6. Southard A, Niermeyer S, Yaron M. Language used in Lake Louise Scoring Sys- gravate or mimic AMS. ${ }^{13,14}$ This factor did not come into play in the present study, because adults refrained from alcohol at high altitudes. A chamber study suggested that obesity may represent a risk factor for AMS in adults..$^{15}$ None of the subjects in our study was obese.

\section{CONCLUSIONS}

Current guidelines suggest pharmacologic prophylaxis for AMS in persons rapidly ascending to high altitude, ${ }^{2}$ in particular in the presence of a history of previous AMS. The findings of the present controlled prospective study provide the scientific foundation for this attitude in adults. In contrast, in children, AMS history is not a useful guide for prescribing or withholding pharmacologic prophylaxis. Moreover, the low prevalence, mild manifestation, and benign course of AMS in chil-

tem underestimates symptoms of acute mountain sickness in 4- to 11-year-old children. High Alt Med Biol. 2007;8(2): $124-130$

7. Mercaldo ND, Lau KF, Zhou XH. Confidence intervals for predictive values with an emphasis to case-control studies. Stat Med. 2007;26(10):2170-2183

8. Wichowski HC, Kubsch SM. The relationship of self-perception of illness and compliance with health care regimens. J Adv Nurs. 1997;25(3):548-553

9. Ross RT. The random nature of cerebral mountain sickness. Lancet. 1985;1(8435): 990-991

10. Mairer K, Wille M, Bucher T, Burtscher M. Prevalence of acute mountain sickness in the Eastern Alps. High Alt Med Biol. 2009; 10(3):239-245

11. Bloch J, Duplain H, Rimoldi SF, et al. Preva- dren rapidly ascending to this altitude at which major tourist destinations are located worldwide suggest that pharmacologic prophylaxis for AMS is not needed, and the use of drugs can be reserved for the treatment of symptoms, if they appear. Finally and most importantly, in children, a history of a previous AMS should also not prompt practitioners to advise against reexposure to high altitudes.

\section{ACKNOWLEDGMENTS}

This work was supported by the Swiss National Science Foundation, the Leenaards Foundation, and the Placide Nicod Foundation.

We are indebted to the study participants and to the International Foundation High Altitude Research Stations Jungfraujoch and Gornergrat for providing the facilities at the Jungfraujoch.

lence and time course of acute mountain sickness in older children and adolescents after rapid ascent to 3450 meters. Pediatrics. 2009;123(1):1-5

12. Roach RC, Maes D, Sandoval D, et al. Exercise exacerbates acute mountain sickness at simulated high altitude. J Appl Physiol. 2000;88 (2):581-585

13. Hackett P, Roach RC, Sutton JR, eds. Management of Wilderness and Environmental Emergencies. CV Mosby Co; 1989

14. Honigman B, Theis MK, Koziol-McLain J, et al. Acute mountain sickness in a general tourist population at moderate altitudes [published correction in Ann Intern Med. 1994; 120(8):698]. Ann Intern Med. 1993;118(8): 587-592

15. Ri-Li G, Chase PJ, Witkowski S, et al. Obesity: associations with acute mountain sickness. Ann Intern Med. 2003;139(4):253-257 


\section{Reproducibility of Acute Mountain Sickness in Children and Adults: A Prospective Study}

Emrush Rexhaj, Sophie Garcin, Stefano F. Rimoldi, Hervé Duplain, Thomas Stuber,

Yves Allemann, Claudio Sartori and Urs Scherrer

Pediatrics; originally published online May 2, 2011;

DOI: $10.1542 /$ peds. 2010-3756

\section{Updated Information \& Services}

Permissions \& Licensing

Reprints including high resolution figures, can be found at:

http://pediatrics.aappublications.org/content/early/2011/04/27 /peds.2010-3756

Information about reproducing this article in parts (figures, tables) or in its entirety can be found online at: http://pediatrics.aappublications.org/site/misc/Permissions.xht $\mathrm{ml}$

Information about ordering reprints can be found online: http://pediatrics.aappublications.org/site/misc/reprints.xhtml

PEDIATRICS is the official journal of the American Academy of Pediatrics. A monthly publication, it has been published continuously since 1948. PEDIATRICS is owned, published, and trademarked by the American Academy of Pediatrics, 141 Northwest Point Boulevard, Elk Grove Village, Illinois, 60007. Copyright @ 2011 by the American Academy of Pediatrics. All rights reserved. Print ISSN: 0031-4005. Online ISSN: 1098-4275.

\section{American Academy of Pediatrics}

